COMECHINGONIA. REVISTA DE ARQUEOLOGÍA

Número 15, 2011, pp. 115-137, Córdoba

ISSN 0326-7911

\title{
ARTE RUPESTRE DE LAS SIERRAS DEL NORTE DE CÓRDOBA, ARGENTINA
}

\author{
Silvana Valeria Urquiza \\ Instituto Superior de Estudios Sociales - CONICET/UNT. Instituto de Arqueología y Museo, Facultad de \\ Ciencias Naturales e IML, Universidad Nacional de Tucumán. silvanaurquiza@yahoo.com
}

Presentado el: 05/07/2011 - Aceptado 27/08/2011

\begin{abstract}
Resumen
Con el objetivo de ampliar el conocimiento para la región se presenta el registro y caracterización de cinco sitios con arte rupestre en la Sierra Norte de la Provincia de Córdoba (Argentina). Hasta el momento se identificaron 172 representaciones pintadas y grabadas, distribuidas en 12 soportes. Como aproximación a los temas plasmados, dinámica, uso de los espacios y la cronológica relativa, se analizan los tipos de ejecución, superposiciones y yuxtaposiciones. Se discute también la correlación estilística con otras regiones de Córdoba, Catamarca y La Rioja. Esto permitió distinguir un grupo estilístico en común, con énfasis en la representación humana, propio del ámbito de las Sierras Pampeanas.
\end{abstract}

Palabras claves: Arte Rupestre, Norte de Córdoba, Sierras Pampeanas.

\begin{abstract}
This paper aims to improve and enhance the regional knowledge. We present the record and the further analysis of five sites having rock art in the Sierra Norte of Córdoba, Argentina. To the moment 172 representations are indentified, which are conformed by pictographs and petroglyphs, distributed in 12 support rocks. As attempt to understand the motifs, the use and spatial dynamics, chronology, the techniques, overpositions and yuxtapositions are analyzed. The stylistical and regional relationship with several sites of Córdoba, Catamarca and La Rioja are discussed. This allows us to recognize a group with stylistic affinities, which emphasizes the human motifs that are typical to the Sierras Pampeanas.
\end{abstract}

Keywords: Rock Art, Córdoba North, Sierras Pampeanas.

\section{Introducción}

Con el objeto de ampliar el conocimiento sobre la arqueología del Norte de la provincia de Córdoba, llevamos a cabo una caracterización de los sitios con arte rupestre relevados hasta el momento en el área, y planteamos una cronología relativa. Anteriormente dimos a conocer el sitio Las Mojarras (Urquiza et al. 2009). En esta oportunidad se incorporan al análisis y discusión las representaciones de cuatro sitios. Estos son: El Río, Agua del Difunto Quinto, La Concebida y El Quebrachal, localizados en los departamentos Sobremonte y Tulumba (Figura 1). 
Los sitios se ubican en las Sierras Pampeanas Orientales sobre los cordones montañosos cámbricos de las Sierras del Norte de Córdoba, limitadas hacia el oeste por las Salinas Grandes y al norte por las Salinas de Ambargasta, quedando un paso natural entre éstas y los sitios en estudio con el sur de la provincia de Catamarca. Las Sierras del Norte de Córdoba continúan hacia el sur de la provincia de Santiago del Estero, donde se denominan Sierra de Ambargasta y de Sumampa (Llambías et al. 2003). El basamento de dichas sierras está constituido por rocas ígneas de composición dominante granítica (Elortegui Palacios et al. 2008) con plutones de granodiorita, granito y cuerpos subvolcánicos (Llambías et al. 2003), caracterizándose el sector centro-norte por granodioritas y granitos con composiciones minerálógicas de horblenda, biotita y epidoto (Bonalumi 1988), además de pequeños afloramientos de metasedimentitas.

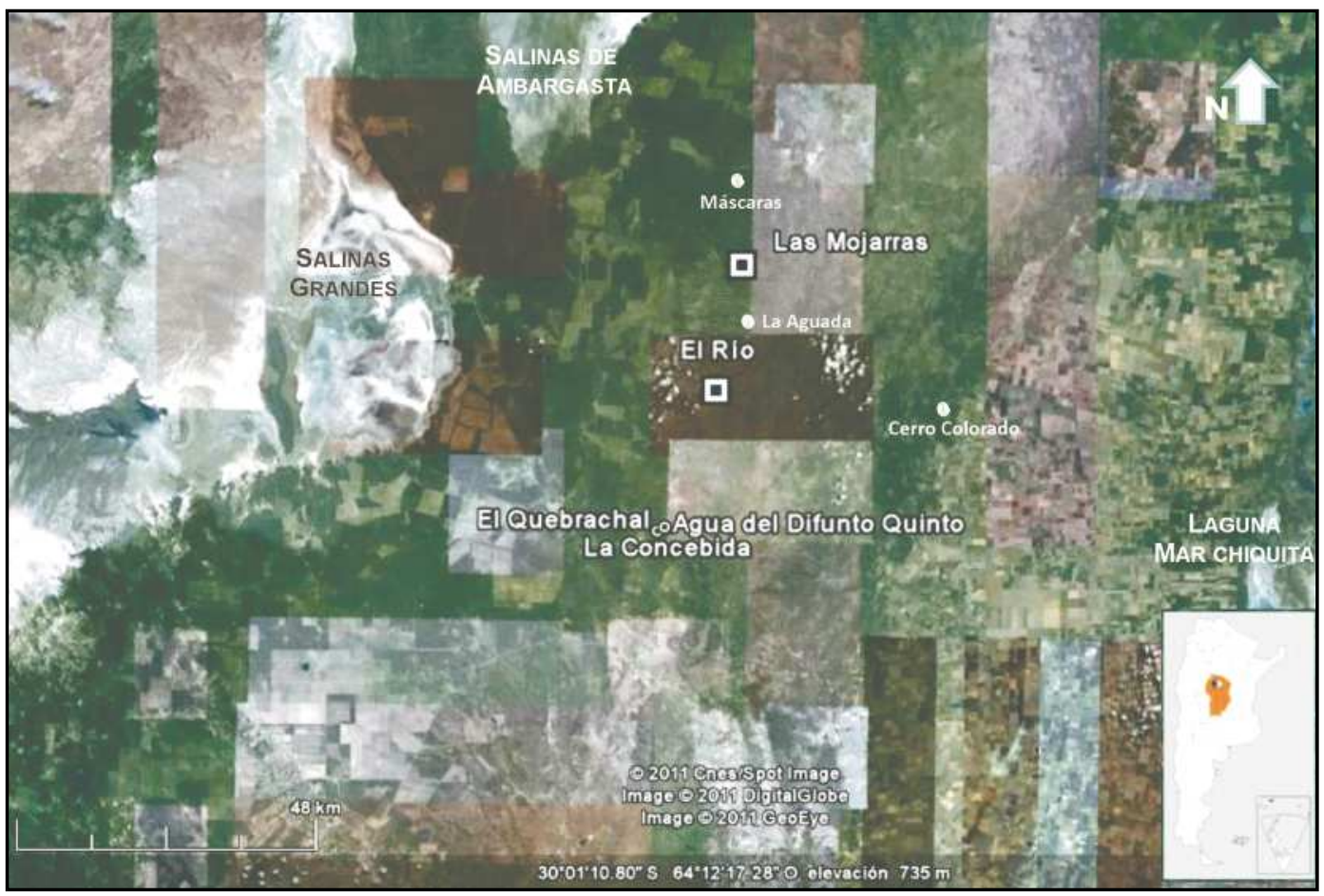

Figura 1. Ubicación del área de estudio y de los sitios relevados en el Norte de la Provincia de Córdoba: Las Mojarras (LM), El Río (ER), El Quebrachal (EQ) y Agua del Difunto Quinto (ADQ).

El área comprende la región Neotropical de dominio Chaqueño (Cabrera 1976), con cauces estacionales y permanentes donde predomina el bosque xerófilo caducifolio con varios estratos, uno superior (mayor a $8 \mathrm{~m}$ ) abierto, dominado por quebracho blanco (Aspidosperma quebracho-blanco) y quebracho colorado (Schinopsis lorentzii) y el molle (Lithraea molleoides); en el estrato medio (4 a $8 \mathrm{~m}$ ) algarrobo (Prosopis sp.), mistol (Zizyphus mistol). El estrato arbustivo es denso y se compone por diversas especies como garabatos (Acacia praecox, Acacia furcatispina), brea (Cercidium australis), chañar (Geoffroea decorticans), tala blanco (Celtis sellowiana Miq.), piquillin (Condalia lineata), sombra de toro (Jodina rhombifolia), jarilla (Larrea divaricada), peperina (Mintostachys mollis) poleo (Lippia turbinata) y palmera caranday 
(Trithrinax campestris). El último estrato es el herbáceo donde predominan cola de caballo (Trichloris crinita), cola de zorro (Setaria spp.) y avenilla (Gouinia paraguarienses) (Codesio y Bilenca 2004), la jarilla y palmera proliferan en zonas de desmonte o incendiadas. Algunos ejemplares de la fauna actual son el zorro gris (Dusicyon griseus), puma (Felis concolor), corzuela (Mazama americana), chancho del monte (Tayassu tajacu), dasipódidos (Tolypeutes matacus; Chaetophractus vellerosus), cuis (Microcavia australis), vizcacha(Lagostomus maximus), gato montés (Oncifelis geoffroyi), perdiz (Nothura maculosa), psitácidos (Myiopsitta monachus; Aratinga acuticaudata), lagartija (Liolaemus sp.), víboras (Crotalus durissus terrificus;Bothrops alternata;B.neuwiedii) y gasterópodos (Spixia pyrgula; Strophocheilidae) entre otras. El clima actual es templado con veranos cálidos y húmedos, mientras que los inviernos son secos y fríos, las precipitaciones anuales de régimen estival ascienden a los $600 \mathrm{~mm}$. La economía en la zona de estudio se basa en la ganadería de caprinos y vacunos; y de menor relevancia son los cultivos de maíz y frutales como cítricos, duraznos y tunas.

\section{Antecedentes del área de investigación}

El arte rupestre de Córdoba ha sido clasificado por Pedersen (1959) en tres zonas: la Sierra de Guasapampa, la Sierra de Comechingones y las Sierras del Norte; en éstas últimas se localiza el área de estudio.

En 1875, el géologo Brackebusch menciona figuras pintadas y grabadas en el cerro Casa del Sol o Intihuasi (Gardner 1931), y años más tarde en 1897, es descripto por Menéndez sin mencionar el arte (González 1963). Las pinturas de Cerro Colorado y Casa del Sol son dadas a conocer en un breve artículo periodístico por Lugones (1903), en 1908 son citadas por Boman y en 1911 Outes propone una clasificación sin un estudio sistemático (González 1980; Ochoa 2008; Urquiza 2006 y 2009). Es G.A. Gardner quien realizaría estudios sistemáticos con fotografías y dibujos en acuarela del arte de diversos sitios de la Sierra Norte, publicándolos en la Universidad de Oxford (Gardner 1931). También F. de Aparicio, registró el arte en Cerro Colorado mediante la toma de fotografías (de Aparicio 1936).

Posteriormente, M. Vignati investiga las pinturas del sitio Máscaras, adscribiendo a las representaciones de la figura humana, atuendos similares a los relatados en las crónicas españolas para los aborígenes de la zona (Vignati 1939). Éste sitio y algunos del área estudiada por Gardner, como La Aguada, ubicado a $8 \mathrm{~km}$ de Las Mojarras, se corresponden desde el punto de vista estilístico con la zona de éste trabajo y presentan motivos pintados de blanco y rojo.

El área de Cerro Colorado ha sido la más intensamente investigada y se localiza hacia el Este de nuestra zona de estudio. Serrano (1945) describe las representaciones de Cerro Colorado, Intihuasi y Máscaras, diferenciando entre petroglifos y pictografías. A. Pedersen (1953-4,1959) documentó mediante la fotografía infrarroja numerosos sitios con pinturas en abrigos rocosos (Cerro Colorado, Cerro Condorhuasi, Cerro Casa del Sol, Cerro Veladero, Desmontes, El Pantanillo y La Quebrada). En 1961, R. González lleva a cabo las primeras excavaciones estratigráficas y luego Pérez Gollán (1968) publica un compendio del arte, y posteriormente surgen numerosas publicaciones de distinta índole sobre estas representaciones (revisión en Urquiza et al. 2009). Por último, en 1987 E. Bolle observa en el sitio Intihuasi el estado de conservación de los motivos y plantea una cronología relativa a través de las modalidades estilísticas (Recalde y Berberián 2005). 
En 1975, Cocilovo y Marcelino presentan el sitio con arte Cerro Puntudo, Dpto. Sobremonte, donde describen un personaje con tocado de plumas, sosteniendo un arco, y la figura de un felino seguido por perros.

Berberián y Nielsen (1985) realizan un análisis comparativo y de acuerdo a las tendencias en la forma de representación distinguen dos tipos de sitios en la provincia de Córdoba: 1) con motivos figurativos naturalistas, destacándose los antropomorfos con detalles, donde incluyen a Máscaras (CSob1), Cerro Puntudo (C.Sob3), Cerro Colorado (C.Sob4), La Aguada (C.Tul2); y 2) con esquematismo en las representaciones figurativas, como Suana (C.Tul3) y Copacabana (C.Isch4). Si bien Berberián releva Suana en la década del 70 sus datos han permanecido inéditos, realizando una breve mención en Berberián y Nielsen (op.cit.).

\section{Emplazamiento y Arte Rupestre}

El área de estudio se encuentra entre los $64^{\circ} 13^{\prime}$ y $64^{\circ} 20^{\prime}$ de longitud Oeste y entre $29^{\circ} 51^{\prime}$ y $30^{\circ} 20^{\prime}$ de latitud Sur, en la Sierra Norte de la provincia de Córdoba. Los sitios fueron agrupados en dos sectores de la misma: Septentrional y Austral. En el Septentrional, se localizan Las Mojarras (LM) y El Río (ER), y aproximadamente a 40 km al SW en línea recta, dentro del sector Austral se ubican El Quebrachal (EQ), La Concebida (LC) y Agua del Difunto Quinto (ADQ). Todos se encuentran entre los 600 y $800 \mathrm{msnm}$, en quebradas angostas con vegetación cerrada, adyacentes a cursos de agua y a vías de circulación naturales que comunican quebradas, y a éstas con las Salinas Grandes y Ambargasta hacia el Norte y con los llanos riojanos hacia el oeste.

Para cada sitio se relevaron las unidades topográficas (UT), el tipo y orientación de los soportes, así como las alturas con respecto al suelo de las representaciones y motivos. Las representaciones pueden conformar motivos o elementos de un motivo (sensu Aschero y Martel 2003-2005). Estas fueron descriptas analizando su morfología, técnica de ejecución y estado de conservación. A la vez se llevó a cabo un inventario de las representaciones apoyado por documentación fotográfica y calcos directos. Se analizaron las repeticiones y asociaciones de motivos en los soportes, relacionando las técnicas de ejecución y los espacios utilizados para plasmar el arte. Las representaciones se clasificaron en Figurativas y No Figurativas, incluyendo en las primeras antropomorfas, zoomorfas y fitomorfas. Mientras que en las No Figurativas se conjugan formas geométricas simples y complejas (líneas, puntos, círculos simples, círculos concéntricos, círculos con punto interior, etc.).

Se analizó la organización en el espacio mediante el registro de la distribución, asociaciones y visibilidad de las representaciones sobre los soportes, a la vez que se establecieron los procesos de alteración natural y antrópica, como modo de acercarnos al problema estilístico. Con el fin de diferenciar formas de representación, los motivos registrados fueron comparados con el arte rupestre de otros sitios de la zona del norte de Córdoba, y sitios ubicados en las provincias de Catamarca y La Rioja.

El arte rupestre ha sido plasmado de manera de ser perceptible visualmente. Puede ser visibilizado a la distancia, o solo ser visible a una muy corta distancia. Nos referimos a la visibilidad del arte y no del soporte, ya que a excepción de LM los demás sitios se confunden en el paisaje de mogotes y monte cerrado. La visibilidad será alta cuando el observador pueda distinguirlo fácilmente a la distancia; con visibilidad media, la percepción visual del arte se reduce por determinadas características topográficas, p.e. vegetación. En estos dos 


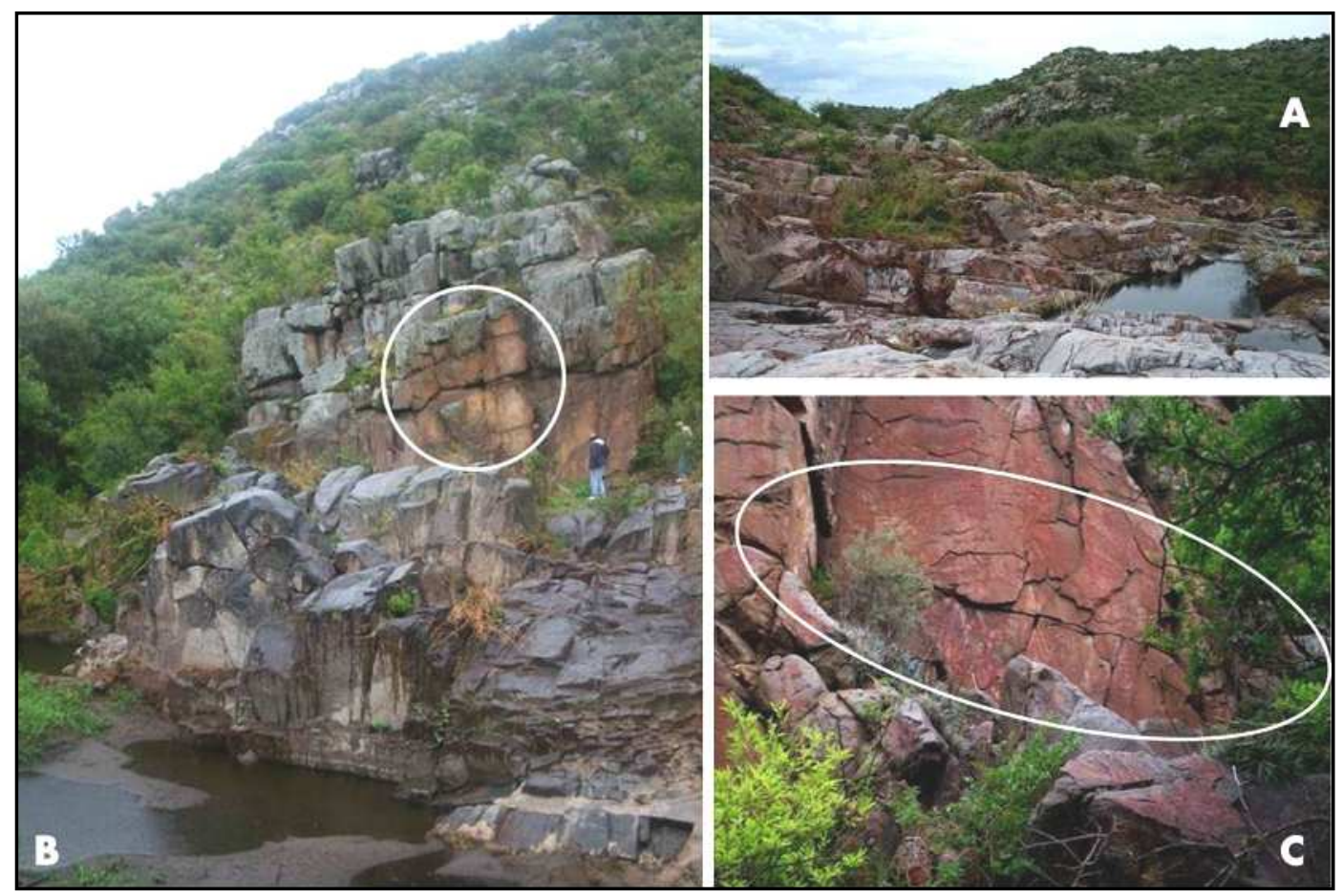

Figura 2. A-Vista panorámica del Sitio Las Mojarras, B y C-Ubicación de las UT I y III respectivamente, se indican las pinturas.

tipos de visibilidad hay una intención del artista de hacer perceptibles las representaciones, pudiendo señalar recursos, caminos, cursos de agua, territorios, etc. Cuando el observador no puede distinguir las representaciones en el paisaje, por estar "ocultas", la visibilidad es baja, p.e. representaciones localizadas dentro de cuevas. Estas representaciones con baja visibilidad, son sin embargo visibles a nivel intra-sitio, para un número restringido de personas que pueden acceder a él, conociendo muy bien su ubicación.

\section{Sector Septentrional de la Sierra Norte}

\section{Sitio Las Mojarras (LM)}

Se localiza a $600 \mathrm{msnm}$, distante $43 \mathrm{Km}$ hacia el este de las Salinas Grandes y a $29 \mathrm{Km}$ hacia el sur de las salinas de Ambargasta. El sitio se encuentra en un valle surcado por el arroyo El Salto, de cauce permanente. El arte se presenta sobre grandes bloques verticales desprendidos de vulcanitas y plutonitas félsicas con superficies planas. La muestra relevada consta de 86 representaciones que constituyen ocho motivos distribuidos en cinco unidades topográficas. Con respecto a la visibilidad del arte en los soportes, las pinturas localizadas en los sectores altos de las paredes verticales presentan alta visibilidad. En cambio, el arte ubicado a bajas alturas, en su mayoría grabados, ofrece mediana a baja visibilidad debido a obstáculos, como la vegetación (Figura 2).

Las técnicas de ejecución corresponden a grabados mediante el picado en surco y pinturas con conjuntos tonales blancos y negros, manifestándose en ambas técnicas motivos figurativos (27\%) y no figurativos (73\%). Entre los figurativos se repiten camélidos, aves y 


\begin{tabular}{|c|c|c|c|c|c|c|c|}
\hline \multirow{2}{*}{$\begin{array}{c}\text { Unidad } \\
\text { Topográfica }\end{array}$} & \multirow{2}{*}{$\begin{array}{c}\text { Total de } \\
\text { Representaciones }\end{array}$} & \multirow{2}{*}{$\begin{array}{c}\mathrm{n} \\
\text { Motivos }\end{array}$} & \multicolumn{2}{|c|}{$\begin{array}{l}\text { Representaciones } \\
\text { Figurativas }\end{array}$} & \multirow[t]{2}{*}{$\begin{array}{l}\text { R. No } \\
\text { Figurativos }\end{array}$} & \multicolumn{2}{|c|}{ Técnicas de Ejecución } \\
\hline & & & Antropomorfos & Zoomorfos & & Grabados & Pintados \\
\hline $\mathrm{I}$ & 12 & 3 & 2 & 6 & 4 & 1 & 11 \\
\hline IIA & 8 & - & - & - & 8 & 8 & - \\
\hline IIB & 11 & 1 & 1 & - & 10 & 11 & - \\
\hline IIIA & 43 & 3 & - & 12 & 31 & 4 & 39 \\
\hline IIIB & 4 & - & - & - & 4 & 4 & - \\
\hline IIIC & 3 & - & - & $=$ & 3 & 2 & 1 \\
\hline IV & 3 & 1 & 1 & 1 & 1 & - & 3 \\
\hline $\mathrm{V}$ & 5 & $=$ & 1 & $=$ & 4 & 5 & - \\
\hline \multirow{2}{*}{ Total } & \multirow{2}{*}{89} & \multirow[t]{2}{*}{8} & $5(5,6 \%)$ & $19(21,4 \%)$ & \multirow{2}{*}{$65(73 \%)$} & \multirow{2}{*}{$35(39,3 \%)$} & \multirow{2}{*}{$54(60,7 \%)$} \\
\hline & & & \multicolumn{2}{|c|}{$24(27 \%)$} & & & \\
\hline
\end{tabular}

Tabla 1. Sitio Las Mojarras. Características morfológicas y técnicas de ejecución por Unidades Topográficas.

en menor proporción antropomorfos. Las pinturas $(60,7 \%)$ se concentran en tres UT (I, IIIA y IV), y los grabados (39,3\%) ocupan casi todas las UT (Tabla 1$)$.

Los soportes que presentan grabados de surco picado continuo se orientan hacia el Oeste, con motivos de círculos simples o compuestos, algunos con un punto central y/o bordes radiados (UT II A y B) y los con círculos concéntricos hacia el Noreste y a mayor altura (UT IIIC) (Figura 3). En el caso de la UT IIB, con picado en surco profundo y líquenes en su interior, a los motivos circulares se suman no figurativos complejos, al igual que en UT

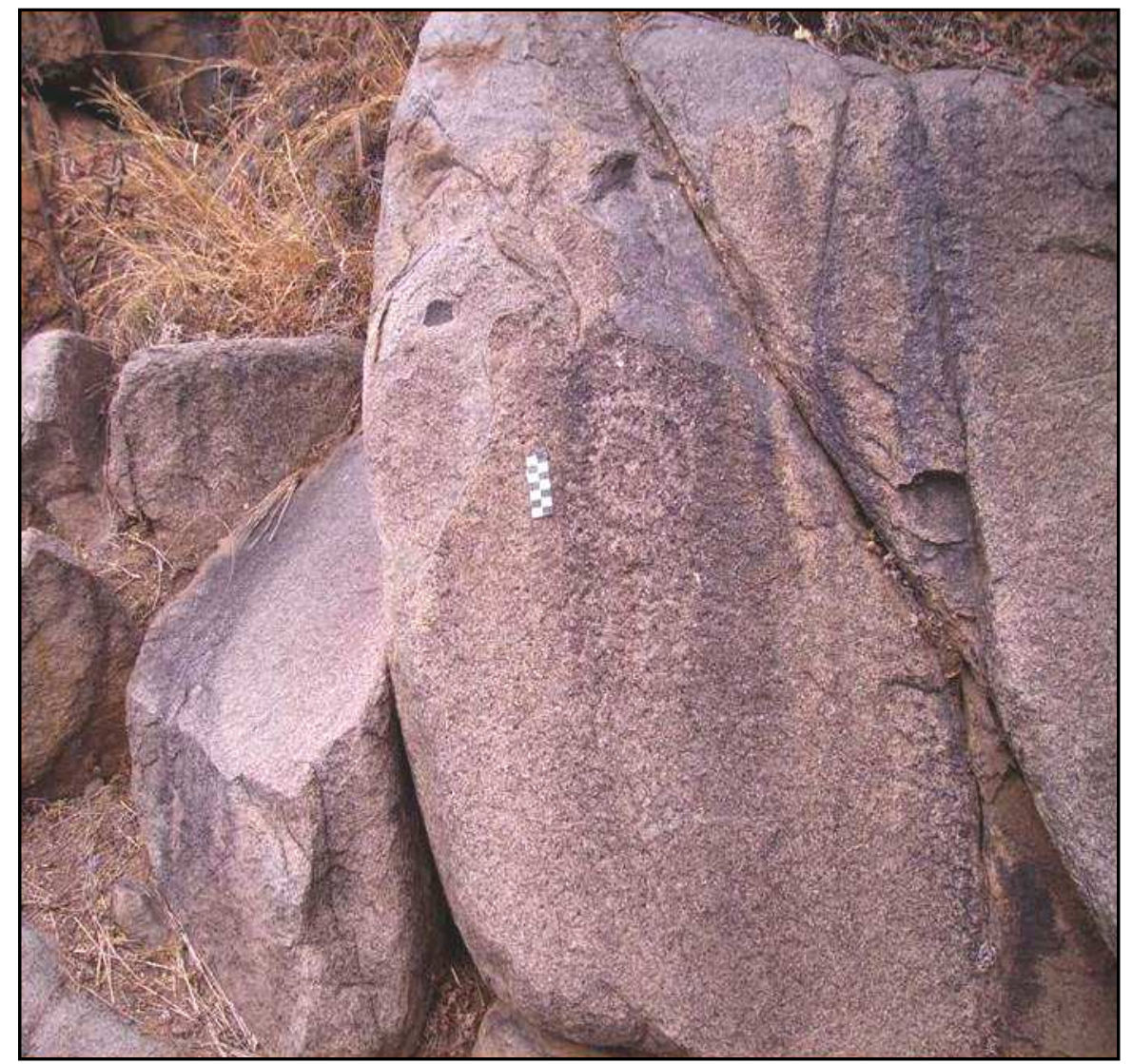

Figura 3. Bloque con motivo abstracto (UT IIA-LM) 


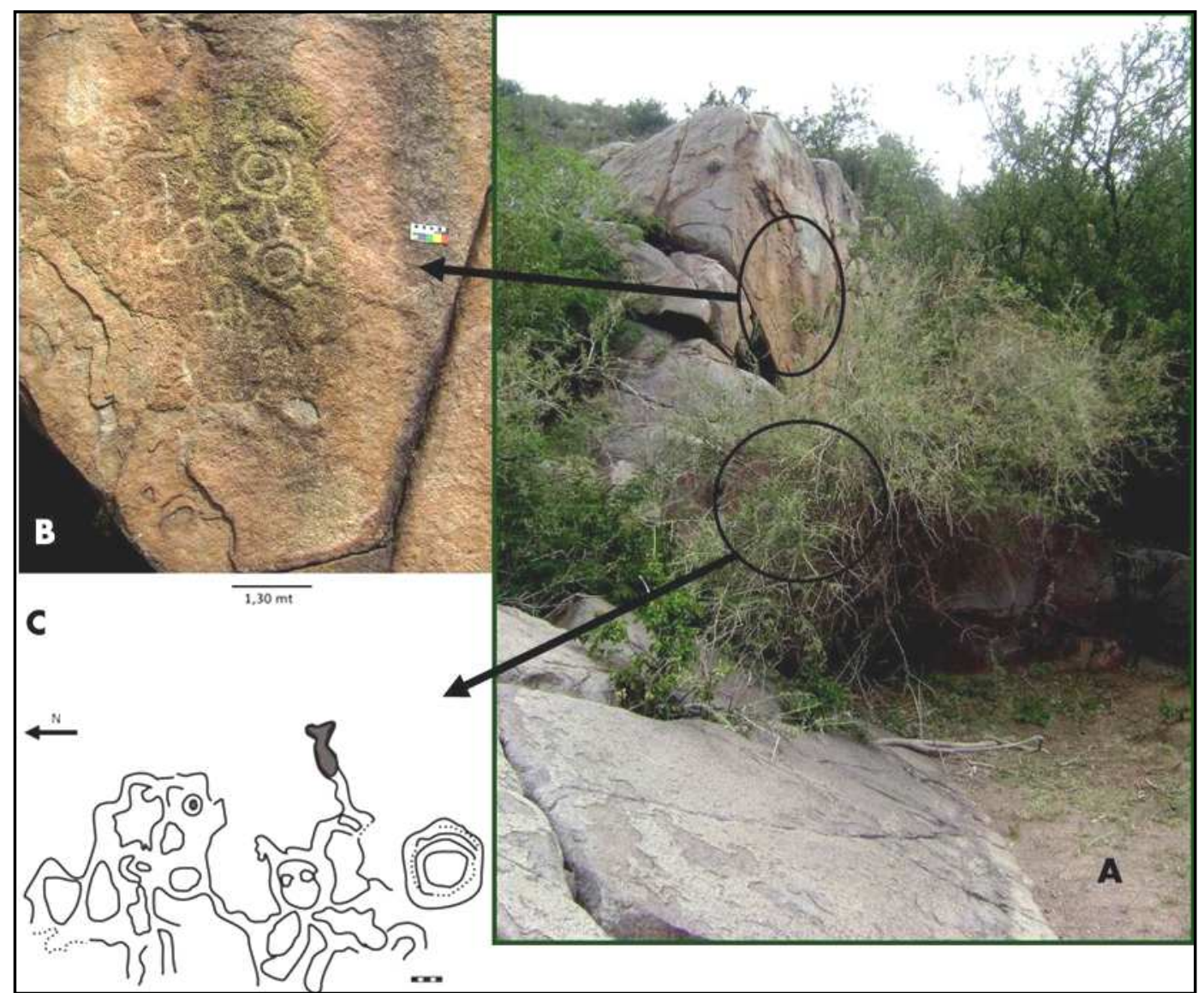

Figura 4. A-Ubicación de los grabados en la UT IIB (LM). B-Motivos abstractos y C-motivo figurativo.

V orientada al Norte. La UT I es un paredón de pátina oscura orientado al Sur, que a baja altura muestra un único grabado no figurativo con dos tipos de líquenes.

Los grabados figurativos, dos antropomorfos, se sitúan en paredes a baja altura emplazadas al Norte. La UT IIB, ubicada a $3 \mathrm{~m}$ del arroyo, presenta una figura antropomorfa central, de frente, con dos prolongaciones como apéndices en su cabeza, y en sus extremidades superiores se distinguen un círculo concéntrico y un motivo complejo (animal?). El motivo grabado en surco picado, se ubica en el lateral de un bloque granitoide, que forma una mesada o pequeño escenario. Por encima de éste, en la pared lindante superior se encuentran grabados en surco picado profundo, formando motivos abstractos orientados al oeste (Figura 4). El antropomorfo de la UT V exhibe un rostro triangular sin indicadores de rasgos faciales y un tocado, los brazos extendidos a los lados y las piernas flexionadas.

Las representaciones pintadas se agrupan en las unidades orientadas al Sur (UT I) y al Norte (UT III y UT IV). La UT III presenta mayor número de no figurativos. En todas las UT son blancas, con excepción de un motivo figurativo zoomorfo blanco que incluye una representación en negro en su interior (UT I) (Figura 12.1A). Los motivos de aves se cir- 
cunscriben a UT I (Figura 5). En la UT IV, a 100 metros de altura del suelo, se encuentra el motivo pintado de mayor tamaño $(0,55 \times 0,45 \mathrm{mts})$ un cuadrúpedo con dos orejas, y por detrás de él un antropomorfo de brazos extendidos sosteniendo un objeto alargado, denominado "el guanaquito" por los pobladores locales, el cual es notable a la distancia (Urquiza et al 2009). El empleo de puntos se repite en los paneles pintados, siempre formando motivos abstractos y como elementos internos de un motivo zoomorfo (Urquiza op cit.).

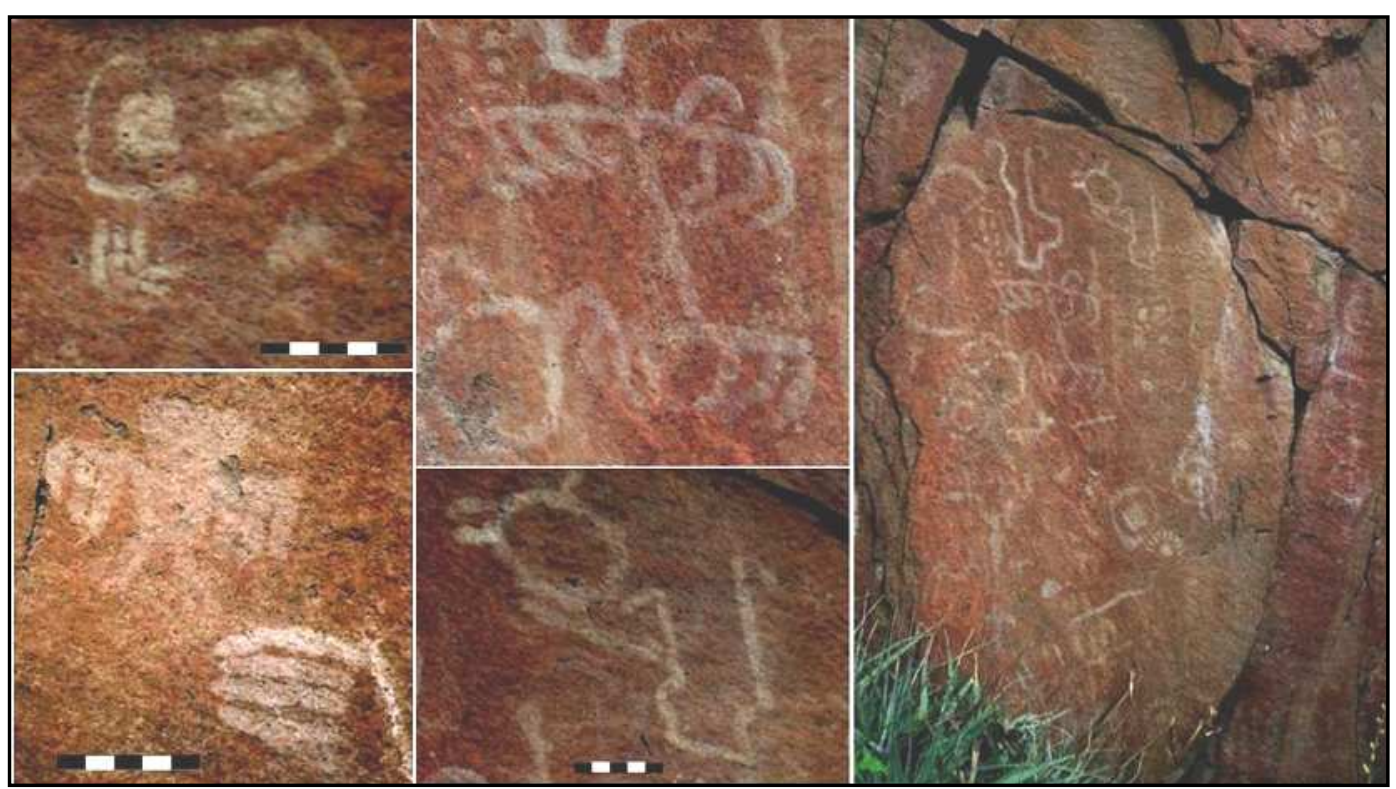

Figura 5. Motivos de aves en UT I (LM)

Sitio El Río (ER)

Se trata de una pequeña cueva a $813 \mathrm{msnm}$, formada por un bloque granitoide con dos aberturas enfrentadas al ras del suelo en sentido E- W. La oquedad formada dentro de la cueva tiene 1,20 m de altura y el piso es de la misma roca. En la pared Sur se encuentra la UT I, formada por una concavidad erosiva del bloque rocoso donde se exhibe una representación zoomorfa, probablemente un felino, formado por 96 elementos (círculos simples, círculos divididos diametralmente y una espiral, entre otros) pintados en color rojo (Tabla 2). Parte de la pintura ha sido alterada por el tizne de un fogón. Sobre la pared $\mathrm{N}$ se localiza la UT II con tres camélidos menores a $10 \mathrm{~cm}$ pintados en blanco, estos presentan dos orejas y cuatro miembros. La visibilidad de ambas UT es baja. De los sitios analizados en este trabajo, El Río es el único donde se utilizó pintura roja (Figura 6).

\begin{tabular}{|c|c|c|c|c|c|c|c|}
\hline \multirow[t]{2}{*}{$\begin{array}{c}\text { Unidad } \\
\text { Topográfica }\end{array}$} & \multirow[t]{2}{*}{$\begin{array}{c}\text { Total de } \\
\text { Representaciones }\end{array}$} & \multirow[t]{2}{*}{$\begin{array}{l}\text { Total de } \\
\text { Elementos }\end{array}$} & \multicolumn{2}{|c|}{ Representaciones Figurativas } & \multirow[t]{2}{*}{$\begin{array}{l}\text { R. No } \\
\text { Figurativas }\end{array}$} & \multicolumn{2}{|c|}{$\begin{array}{c}\text { Técnicas de } \\
\text { ejecución: } \\
\text { Pintados } \\
\end{array}$} \\
\hline & & & Antropomorfos & Zoomorfos & & Rojo & Blanco \\
\hline I & 1 & 96 & - & 1 & $=$ & 1 & - \\
\hline II & 3 & 3 & $=$ & 3 & I. & $=$ & 3 \\
\hline Total & 4 & 99 & - & $4(100 \%)$ & $=$ & 4( & $00 \%)$ \\
\hline
\end{tabular}

Tabla 2. Sitio El Río. Características morfológicas y técnicas de ejecución. 


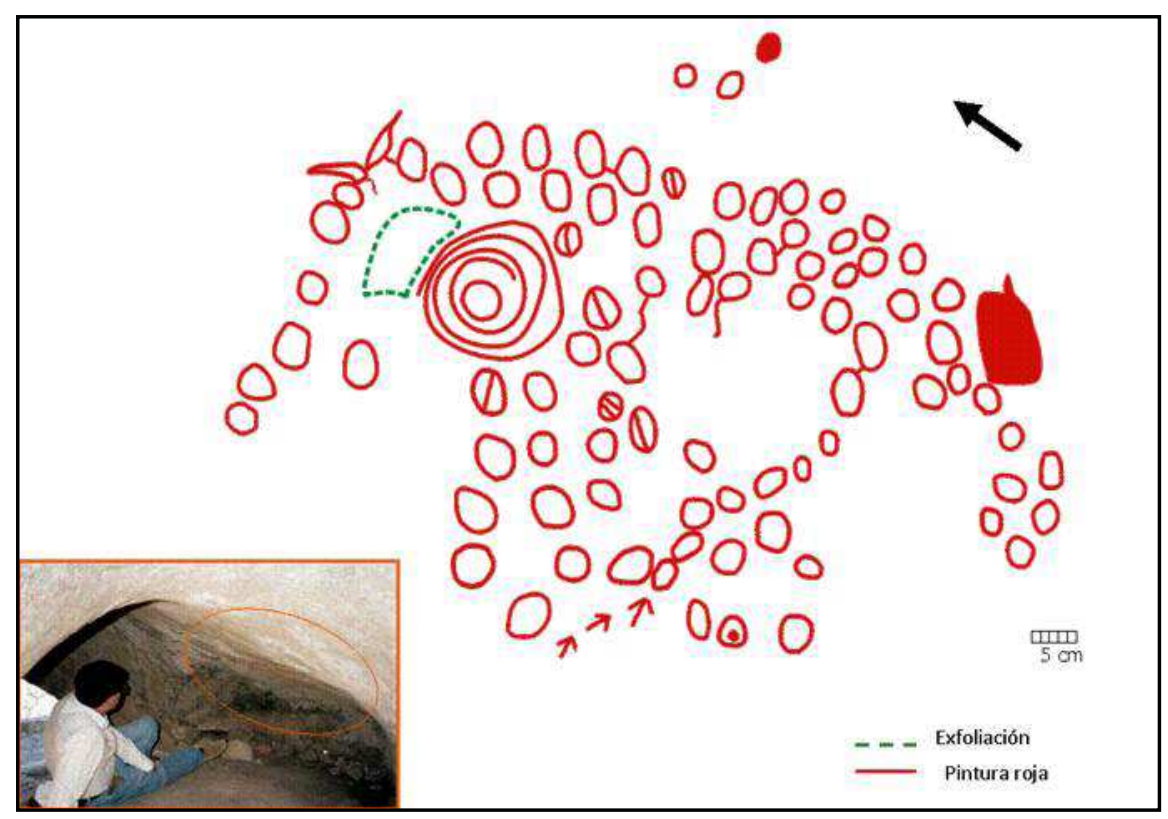

Figura 6. Sitio El Río. Localización de la UT I y motivo a escala.

\section{Sector Austral de la Sierra Norte}

En la zona conocida como Suana se registraron diversos sitios. En este trabajo se relevaron los que presentan arte rupestre.

\section{Sitio Agua del Difunto Quinto (ADQ)}

En el margen de un arroyo permanente de sentido E-W, se localizan grandes bloques granitoides, y tres de ellos contienen cuatro morteros de entre 15 y $25 \mathrm{~cm}$ de diámetro. El mortero de mayor tamaño se encuentra solo en un bloque desgastado en forma cóncava. En las inmediaciones del grupo de morteros, a $725 \mathrm{msnm}$ sobre la ladera Norte, se emplaza una cueva dentro de un gran bloque granitoide. El interior de la cueva es de forma cilíndrica, con 1,40m de alto x $6 \mathrm{~m}$ de largo y 1,90m de ancho, presentando una pequeña abertura al Sur, y otra de mayor tamaño hacia el Noreste, con una antecámara sin arte rupestre que se perfila hacia el Norte (Figura 7).

Se definieron dos unidades topográficas (Tabla 3), la UT I ubicada en la pared Este, cuenta con 43 representaciones $(93,5 \%)$ pintadas en blanco que conforman 10 motivos, de éstas, 30 son no figurativas y 13 figurativas, dominando los zoomorfos sobre los antropomorfos. Las representaciones se ubican entre los 0,66 y 1,35 m sobre la superficie del terreno. Entre los motivos animales muestreados se agrupan, un iguanoide, una huella de felino y camélidos cuadrúpedos, con dos orejas y cola hacia abajo. En uno de los motivos se encuentran dos camélidos de espaldas. En el panel se observan tres motivos antropomorfos, uno pequeño de apariencia simiesca, otro simplista posicionado de frente y el más complejo se encuentra de perfil y presenta ornamentos cefálicos y sostiene un arma (arco y flecha?). 

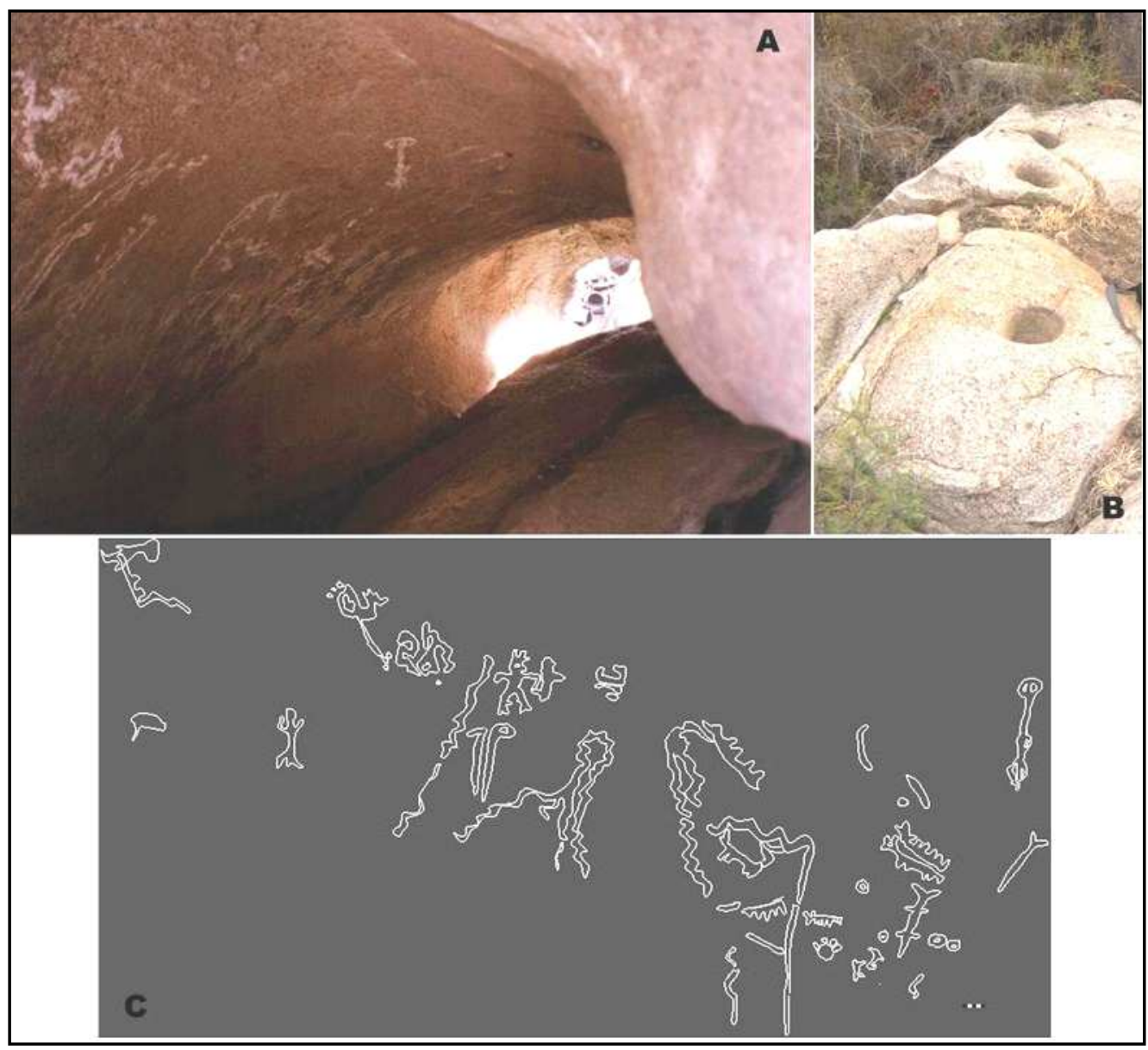

Figura 7. Sitio Agua del Difunto Quinto. A- Ubicación de la UT I; B- Morteros localizados en las inmediaciones de la cueva; C-Calco de la UT I.

\begin{tabular}{|c|c|c|c|c|c|c|}
\hline \multirow{2}{*}{$\begin{array}{c}\text { Unidad } \\
\text { Topográfica }\end{array}$} & \multirow{2}{*}{$\begin{array}{c}\text { Total de } \\
\text { Representaciones }\end{array}$} & \multirow{2}{*}{$\begin{array}{c}\mathrm{n} \\
\text { Motivos }\end{array}$} & \multicolumn{2}{|c|}{ Representaciones Figurativas } & \multirow{2}{*}{$\begin{array}{l}\text { R. No } \\
\text { Figurativas }\end{array}$} & \multirow{2}{*}{$\begin{array}{l}\text { Técnicas de } \\
\text { ejecución: } \\
\text { Pintados }\end{array}$} \\
\hline & & & Antropomorfos & Zoomorfos & & \\
\hline $\mathrm{I}$ & 43 & 10 & 3 & 10 & 30 & $43(93,5 \%)$ \\
\hline II & 3 & 3 & - & 1 & 2 & $3(6,5 \%)$ \\
\hline \multirow{2}{*}{ Total } & \multirow{2}{*}{46} & \multirow{2}{*}{13} & $3(6,5 \%)$ & $11(24 \%)$ & \multirow[b]{2}{*}{$32(69,5 \%)$} & \multirow[b]{2}{*}{$46(100 \%)$} \\
\hline & & & \multicolumn{2}{|c|}{$14(30,5 \%)$} & & \\
\hline
\end{tabular}

Tabla 3. Sitio Agua del Difunto Quinto. Características morfológicas y técnicas de ejecución.

La mayor parte del piso de la cueva es de roca, excepto debajo de la UT I donde hay sedimento cubierto por hojarasca. Sobre la pared Oeste se ubica UT II, con 3 representaciones $(6,5 \%)$, exhibiendo un camélido de cuatro patas y dos orejas, y dos representaciones lineales pintadas en blanco. Las UT presentan baja visibilidad desde el exterior al estar en el interior de la cueva.

\section{Sitio El Quebrachal (EQ)}

Es un alero de roca soporte granítica a $770 \mathrm{msnm}$, con tres representaciones pintadas en blanco agrupadas en una UT (Tabla 4). Estas cuentan con un posible antropomorfo de 


\begin{tabular}{|c|c|c|c|c|c|c|c|}
\hline \multirow[t]{2}{*}{\begin{tabular}{|c|} 
Unidad \\
Topográfica
\end{tabular}} & \multirow{2}{*}{$\begin{array}{c}\text { Total de } \\
\text { Representaciones }\end{array}$} & \multirow{2}{*}{$\begin{array}{c}\mathrm{n} \\
\text { Motivos }\end{array}$} & \multirow{2}{*}{$\begin{array}{c}\text { Total de } \\
\text { Elementos }\end{array}$} & \multicolumn{2}{|c|}{$\begin{array}{l}\text { Representaciones } \\
\text { Figurativas }\end{array}$} & \multirow[t]{2}{*}{$\begin{array}{c}\text { R. No } \\
\text { Figurativa }\end{array}$} & \multirow{2}{*}{$\begin{array}{l}\text { Técnicas de } \\
\text { ejecución: } \\
\text { Pintados }\end{array}$} \\
\hline & & & & Antropomorfos & Fitomorfos & & \\
\hline I & 3 & 2 & 11 & 1 & 1 & 1 & 3 \\
\hline \multirow{2}{*}{ Total } & \multirow{2}{*}{3} & \multirow{2}{*}{2} & \multirow{2}{*}{11} & $1(33,3 \%)$ & $1(33,3 \%)$ & \multirow{2}{*}{$\begin{array}{c}1 \\
(33,3 \%)\end{array}$} & \multirow{2}{*}{$3(100 \%)$} \\
\hline & & & & \multicolumn{2}{|c|}{$2(66,7 \%)$} & & \\
\hline
\end{tabular}

Tabla 4. Sitio alero El Quebrachal. Características morfológicas y técnicas de ejecución.

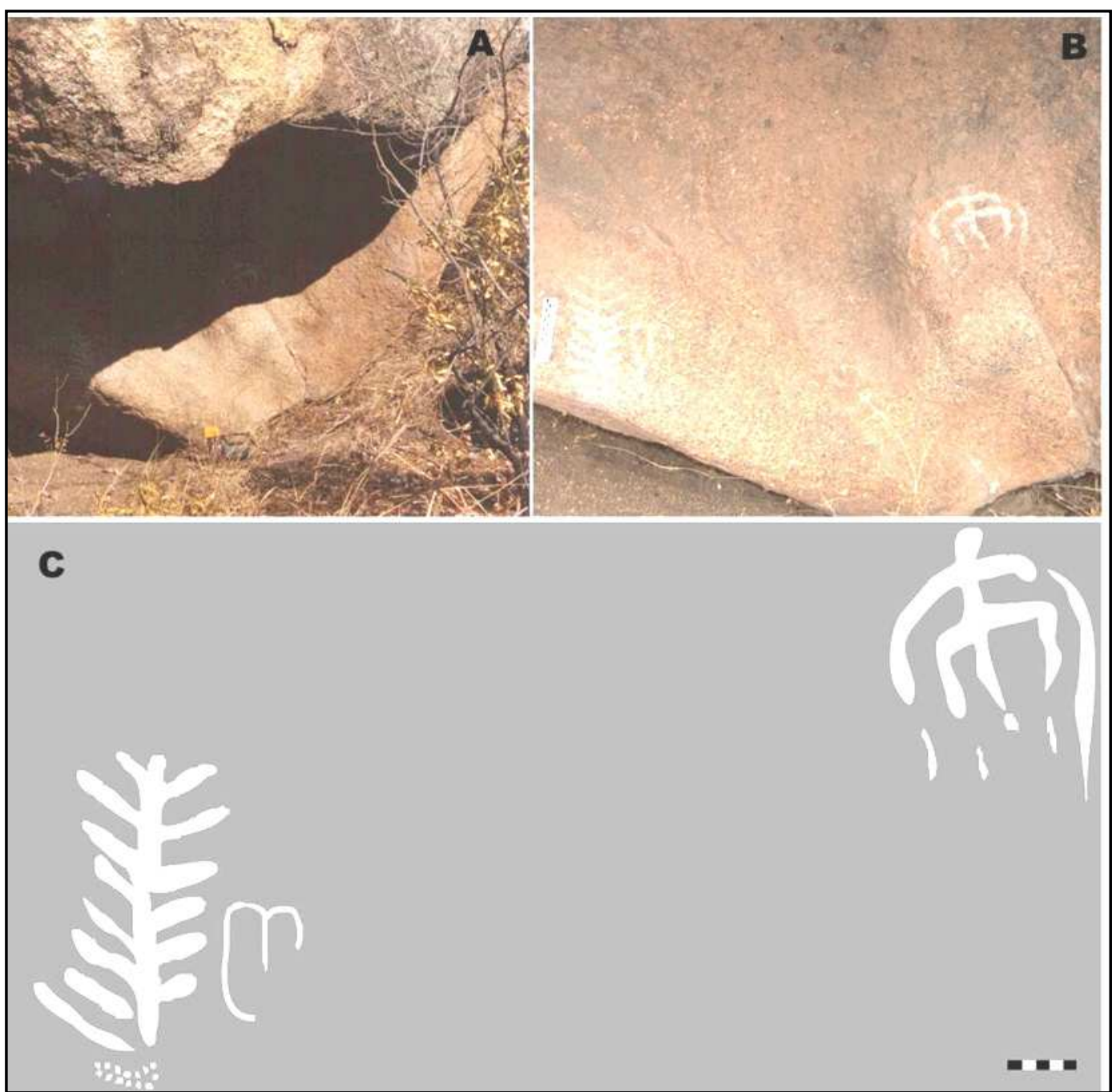

Figura 8. Sitio El Quebrachal. A y B- Ubicación de las pinturas en el alero; C-Calco de la UT I.

extremidades alargadas hacia abajo, separado de las otras representaciones (fitomorfa y no figurativa) por una pequeña oquedad en la roca soporte (Figura 8). Hacia el Noroeste del alero, a tres metros, se localiza un gran bloque que conforma una cueva en su interior sin arte rupestre, de aproximadamente $12 \mathrm{~m}^{2}$ con dos aberturas y piso de tierra, e inmediata a ésta se encuentra otra pequeña cueva con una abertura cerrada intencionalmente con rocas. La visibilidad de los motivos es media. 


\section{Sitio La Concebida (LC)}

En la misma quebrada que EQ, a $600 \mathrm{~m}$ hacia el Sur, se encuentra el sitio LC sobre la ladera de la sierra. Es una cueva a $750 \mathrm{msnm}$, conformada por un bloque granitoide y piso de tierra, donde se registraron dos UT con representaciones pintadas en blanco, entre las cuales el $83,4 \%$ son no figurativas. La UT I comprende el $70 \%$ de las representaciones, mientras que en el 30\% restante se ubica en el muro adyacente, denominado UT II. Esta última incluye ocho representaciones no figurativas y un motivo antropomorfo con las extremidades prolongadas, similar al registrado en el EQ (Tabla 5). La UT I se sitúa dentro de una oquedad natural del soporte contra el suelo, de 0,60 m de altura. Comprende como

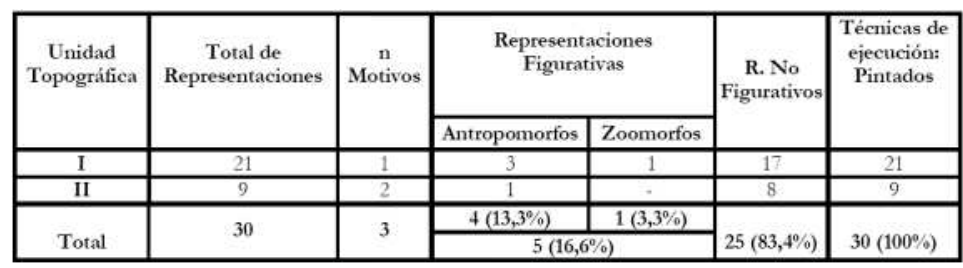

Tabla 5. Sitio La Concebida. Características morfológicas y técnicas de ejecución por unidad topográfica.

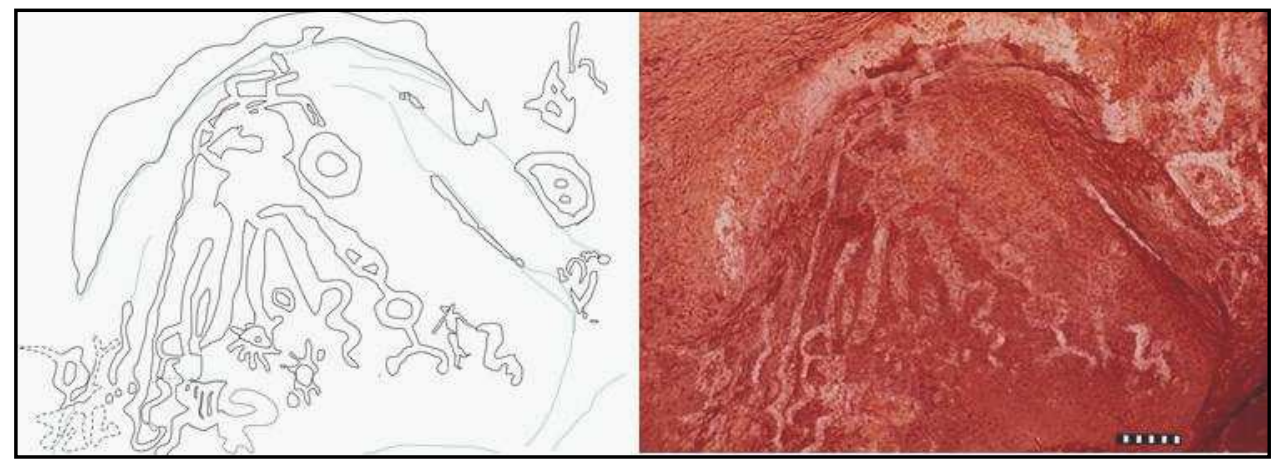

Figura 9. Sitio La Concebida. Motivo central de UT I.

motivo central un antropomorfo exhibiendo apéndices a modo de un tocado, del torso penden elementos y otro antropomorfo de menor tamaño. En la parte inferior del motivo se ubica otro antropomorfo de cabeza triangular junto a un serpentiforme. Los bordes de la oquedad presentan pintura blanca y representaciones no figurativas delimitando en su interior el motivo descripto (Figura 9). La visibilidad de ambas UT es baja desde el exterior de la cueva.

\section{Cotejo intersitios}

Hasta el momento se relevaron en la Sierra Norte cinco sitios con un total de 12 Unidades Topográficas, de las cuales siete se localizan en el Sector Septentrional y cinco en el Austral (Tabla 6). Se cuantificaron 172 representaciones, algunas de las cuales conforman 31 motivos, con un bajo a nulo porcentaje de superposiciones y alto de yuxtaposiciones.

Las representaciones se concentran en Las Mojarras (52\%) y Agua del Difunto Quinto (27\%), configurando en éste último la principal cantidad de motivos con el $41,9 \%$. En todos los sitios se registran figurativas $(28,5 \%)$ y no figurativas $(71,5 \%)$, con excepción del sitio 


\begin{tabular}{|c|c|c|c|c|c|c|c|c|c|c|}
\hline \multirow{3}{*}{$\begin{array}{l}\text { Sitio y } \\
\text { Sector }\end{array}$} & \multicolumn{4}{|c|}{ Representaciones } & \multirow{3}{*}{$\begin{array}{l}\text { Total } \\
\text { de } \mathrm{R}\end{array}$} & \multirow{3}{*}{$\begin{array}{c}\mathrm{n} \\
\text { Motivos }\end{array}$} & \multirow{3}{*}{$\begin{array}{c}\mathrm{n} \\
\text { UT }\end{array}$} & \multirow{3}{*}{$\begin{array}{l}\text { Tipo de } \\
\text { Soporte y } \\
\text { Litología }\end{array}$} & \multirow{3}{*}{$\begin{array}{l}\text { Técnica de } \\
\text { Ejecución }\end{array}$} & \multirow{3}{*}{ Visibilidad } \\
\hline & \multicolumn{3}{|c|}{ F } & \multirow{2}{*}{ NF } & & & & & & \\
\hline & A & $\mathrm{Z}$ & F & & & & & & & \\
\hline $\begin{array}{c}\text { Las } \\
\text { Mojarras } \\
\text { SS }\end{array}$ & 5 & 19 & - & 65 & $\begin{array}{c}89 \\
(52 \%)\end{array}$ & $\begin{array}{c}8 \\
(25,8 \%)\end{array}$ & 5 & $\begin{array}{c}\text {-Paredes } \\
\text { verticales y } \\
\text { Bloques } \\
\text { aislados } \\
\text { - Vulcanitas } \\
\text { y plutonitas } \\
\text { félsicas }\end{array}$ & $\begin{array}{c}\text {-Pintado: } \\
\text { Blanco y } \\
\text { Negro } \\
\text {-Grabado: } \\
\text { Surco } \\
\text { picado }\end{array}$ & Alta/Media \\
\hline $\begin{array}{l}\text { El Río } \\
\text { SS }\end{array}$ & - & 4 & = & - & $\begin{array}{c}4 \\
(2 \%)\end{array}$ & $\begin{array}{c}4 \\
(12,9 \%)\end{array}$ & 2 & $\begin{array}{l}\text {-Cueva } \\
\text {-Granitoide }\end{array}$ & $\begin{array}{l}\text { Pintado: } \\
\text { Rojo y } \\
\text { Blanco }\end{array}$ & Baja \\
\hline $\begin{array}{c}\text { Agua del } \\
\text { Difunto } \\
\text { Quinto } \\
\text { SA }\end{array}$ & 3 & 11 & - & 32 & $\begin{array}{c}46 \\
(27 \%)\end{array}$ & $\begin{array}{c}13 \\
(41,9 \%)\end{array}$ & 2 & $\begin{array}{c}\text {-Cueva } \\
\text {-Granitoide }\end{array}$ & $\begin{array}{c}\text { Pintado: } \\
\text { Blanco }\end{array}$ & Baja \\
\hline $\begin{array}{c}\text { El } \\
\text { Quebrachal } \\
\text { SA }\end{array}$ & 1 & - & 1 & 1 & $\begin{array}{c}3 \\
(2 \%)\end{array}$ & $\begin{array}{c}3 \\
(9,7 \%)\end{array}$ & 1 & $\begin{array}{c}\text {-Alero } \\
\text {-Granitoide }\end{array}$ & $\begin{array}{c}\text { Pintado: } \\
\text { Blanco }\end{array}$ & Media \\
\hline $\begin{array}{c}\text { La } \\
\text { Concebida } \\
\text { SA } \\
\end{array}$ & 4 & 1 & - & 25 & $\begin{array}{c}30 \\
(17 \%)\end{array}$ & $\begin{array}{c}3 \\
(9,7 \%)\end{array}$ & 2 & $\begin{array}{l}\text {-Cueva } \\
\text {-Granitoide }\end{array}$ & $\begin{array}{l}\text { Pintado: } \\
\text { Blanco }\end{array}$ & Bajo \\
\hline \multirow{2}{*}{$\begin{array}{c}\text { Total y } \\
\text { porcentajes }\end{array}$} & $\begin{array}{c}13 \\
7,6 \%\end{array}$ & $\begin{array}{c}35 \\
20,3 \%\end{array}$ & $\begin{array}{c}1 \\
0,6 \%\end{array}$ & \multirow{2}{*}{$\begin{array}{r}123 \\
71,5 \%\end{array}$} & \multirow{2}{*}{$\begin{array}{l}172 \\
100 \%\end{array}$} & \multirow[b]{2}{*}{$100 \%$} & \multirow[t]{2}{*}{12} & & & \\
\hline & \multicolumn{3}{|c|}{$\begin{array}{c}49 \\
28,5\end{array}$} & & & & & & & \\
\hline
\end{tabular}

Tabla 6. Características morfológicas y técnicas de ejecución del arte rupestre en los sitios analizados de la Sierra Norte (Prov. Córdoba).

F: Figurativas; NF: No Figurativas; A: Antropomorfas; Z: Zoomorfas; F:Fitomorfas; R: Representaciones; UT: Unidades Topográficas; SS: Sector Septentrional; AS: Sector Austral.

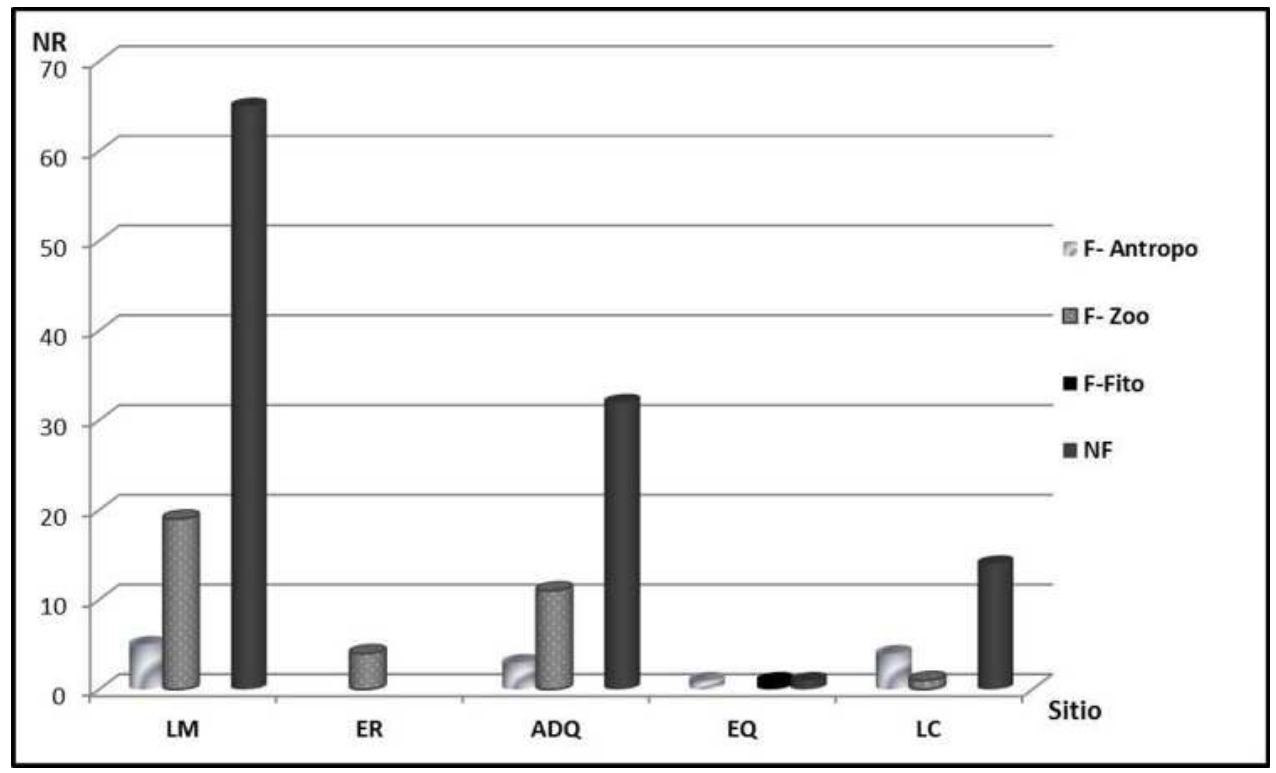

Figura 10. Número y tipo de representaciones por sitio.

NF: No Figurativas, F: Figurativas (Antropomorfas, Zoomorfas, Fitomorfas) LM: Las Mojarras, ER: El Río, ADQ:Agua del Difunto Quinto, LC: La Concebida 
El Río donde sólo encontramos zoomorfos (Figura 10). Las no figurativas incluyen diseños geométricos lineales, zigzag, líneas rectas cortadas por círculos, círculos simples y concéntricos entre otros. Los figurativos cuentan con un fitomorfo (EQ) y zoomorfos $(20,3 \%)$ como huellas de felinos (LM y LC), iguánidos (LM y ADQ), ofidios (LM y LC), aves (LM), un posible felino (ER) y camélidos (LM, ER y ADQ) (Figura 11). Los antropomorfos se presentan en todos los sitios (7,6\%), excepto en ER. En LM encontramos cinco motivos antropomorfos, tres de los cuales son pintados y dos grabados de mayores proporciones.

En cuanto a la técnica, en LM encontramos representaciones grabadas (n: 35) y pintadas (n: 54), se empleó el picado en surco y en las pinturas los colores blanco y negro. En los otros sitios estudiados no se registraron grabados. En ER los motivos están pintados de coloración roja (n:1) y blanca (n:3), y solo de blanco en EQ(n:3), LC (n:30)y ADQ (n:46).

Las Mojarras es el único sitio a cielo abierto y donde se emplearon como soportes bloques aislados y paredes verticales de vulcanitas y plutonitas félsicas, éstas últimas han brindando alta/media visibilidad a las representaciones en general (Urquiza et al. 2009). En los sitios restantes, los soportes se conforman por las paredes internas de tres cuevas y un alero, de litología plutónica granitoide, los cuales resguardan las representaciones y otorgan baja visibilidad (Tabla 6).

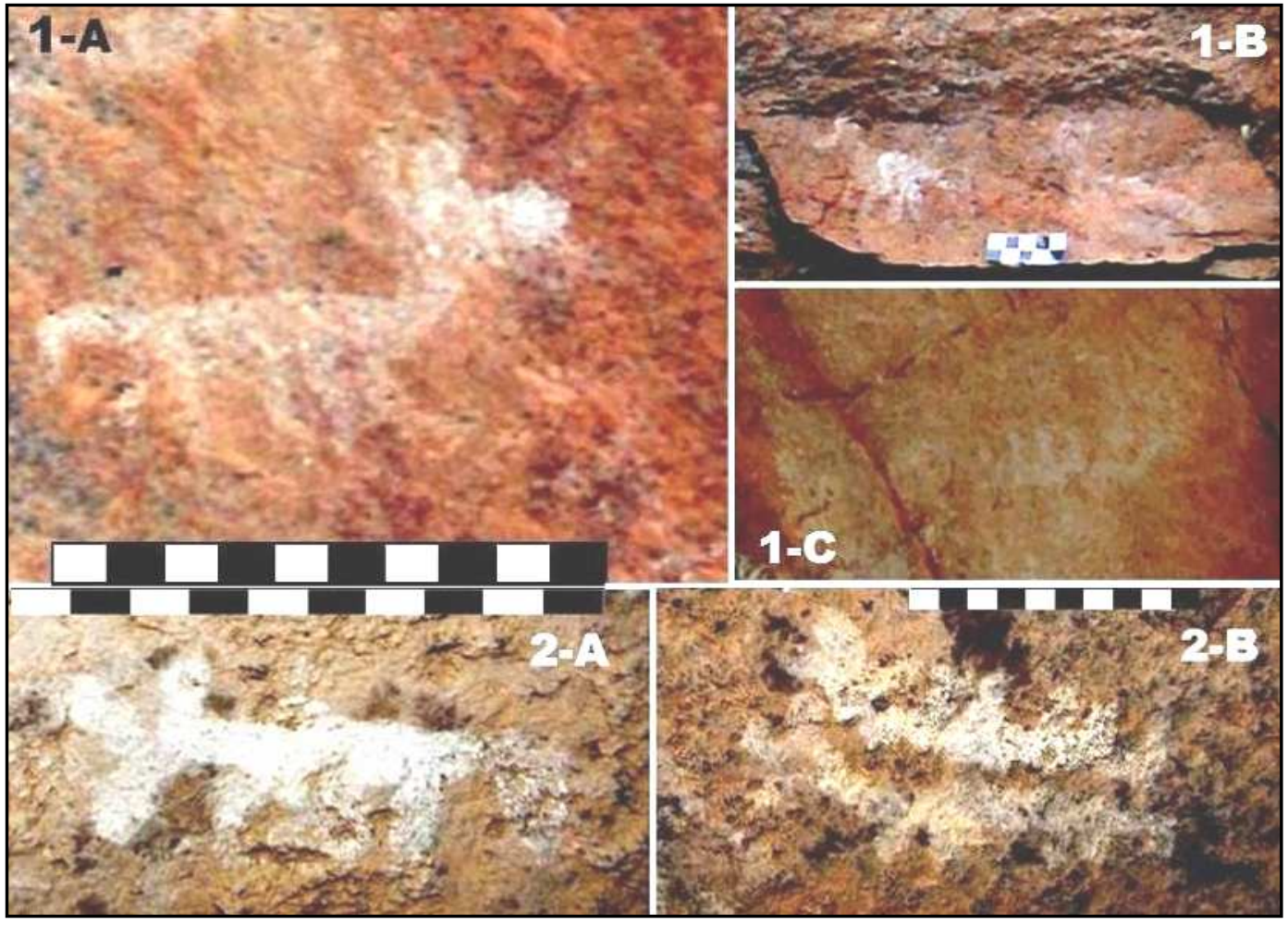

Figura 11. Motivos de camélidos. 1- Sitio Las Mojarras, A: UT IIIA; B y C: UT I; 2-A y B. Sitio Agua del Difunto Quinto UT I. 
En cuanto a la preservación del arte hemos observado en sucesivas campañas el desvanecimiento de pinturas y la degradación de los soportes, los que han sido cubiertos de líquenes, presumimos por un aumento de la humedad en los últimos años.

En todos los sitios se registraron y recolectaron evidencias materiales en la superficie de las áreas relacionadas al arte rupestre. En el sitio ADQ se recuperaron lascas de ópalo, fragmentos de cerámica tosca y en LM fragmentos de cerámica tosca oxidante y una punta triangular apedunculada de cuarzo blanco (UT V) asignable a momentos agropastioriles (Urquiza et al. op cit.). Sobre el faldeo de la sierra, frente a los paneles pintados de UT III, se localiza una cueva sin arte con restos óseos de camélidos en superficie. Ambos sitios presentan morteros sobre los bloques de rocas que bordean los arroyos. Los sitios ADQ, LC y EQ, son cercanos al antiguo poblado minero de Suana, donde se recuperaron fragmentos de cerámica símil Sunchituyoj, puntas de cuarzo y un punzón óseo ${ }^{1}$. Un dato particular se vincula a la posible existencia de un cuerpo humano, el cual según los lugareños, se encuentra enterrado en la cueva de ADQ. Es probable que este registro material se encuentre asociado a las representaciones rupestres pero serán las excavaciones arqueológicas ulteriores las que reforzarán estos vínculos contextuales.

Los antropomorfos fueron clasificados tentativamente en grupos, que si bien son construcciones arbitrarias, cada uno involucra diversos estándares manteniendo un estilo (sensu Troncoso 2003). La identidad de este estilo, se manifiesta por la elección de un tipo de soporte, las técnicas empleadas, las representaciones y su ubicación en el espacio (Figura 12).

1- Figura posiblemente humana, de perfil hacia su izquierda?. Presenta un flanco con la extremidad superior extendida y la inferior flexionada, su tamaño varía entre 10-20 cm. Técnica: pintado. Localizado en LM (UT I) y en ADQ (UT I).

2- Figura erguida de frente, con cráneo redondeado exponiendo apéndices y/o tocado. Exhibe extremidades superiores e inferiores, en algunos casos ostentan objetos, armas y/o animales. Su tamaño varía entre $20-60 \mathrm{~cm}$. Localizado en ADQ (UT I), LC (UT I) y LM (pintado- UT I), y LM (grabado-UT IIB).

3- Figura estilizada de frente, con cráneo subtriangular, piernas y pies definidos, en algunos casos se distingue el atavío, y probable actitud dinámica de las extremidades inferiores. El antropomorfo pende de un personaje de mayor tamaño. Sus dimensiones rondan los $10 \mathrm{~cm}$. Se localiza en LC (UT I) y su técnica es pintado.

4- Figura de frente, estilizada y escueta, de cráneo pequeño. Extremidades superiores e inferiores flexionadas y alargadas hacia abajo, ostenta un apéndice entre las inferiores. Técnica: pintado. Ubicado en LC (UT II) y EQ (UT I).

5- Figura de frente, cráneo triangular con tocado, rasgos faciales ausentes, extremidades superiores alargadas, miembros inferiores flexionados, y posible atavío. Técnica: grabado. Situado en LM (UT V).

Las figuras del grupo 1 se vinculan a zoomorfos (huella de felino, camélidos e iguánidos) y a círculos y líneas. Si bien estamos en duda sobre la posible representación de cuerpos humanos, se toma en cuenta la alternativa hasta tener más evidencias al respecto. En el caso de los personajes del grupo 2, uno de ellos sostiene una figura animal en una mano y elementos indistintos en la otra (LM). El personaje antropomorfo central del EQ muestra en las extremidades a las figuras del grupo 3 junto con elementos símiles a armas, huella de felino, un ofidio, círculos y líneas. Las figuras del grupo 4 se asocian a representaciones no figurativas en zigzag, circulares y lineales; y las del grupo 5 con motivos circulares encadenados y otros con radiaciones. 


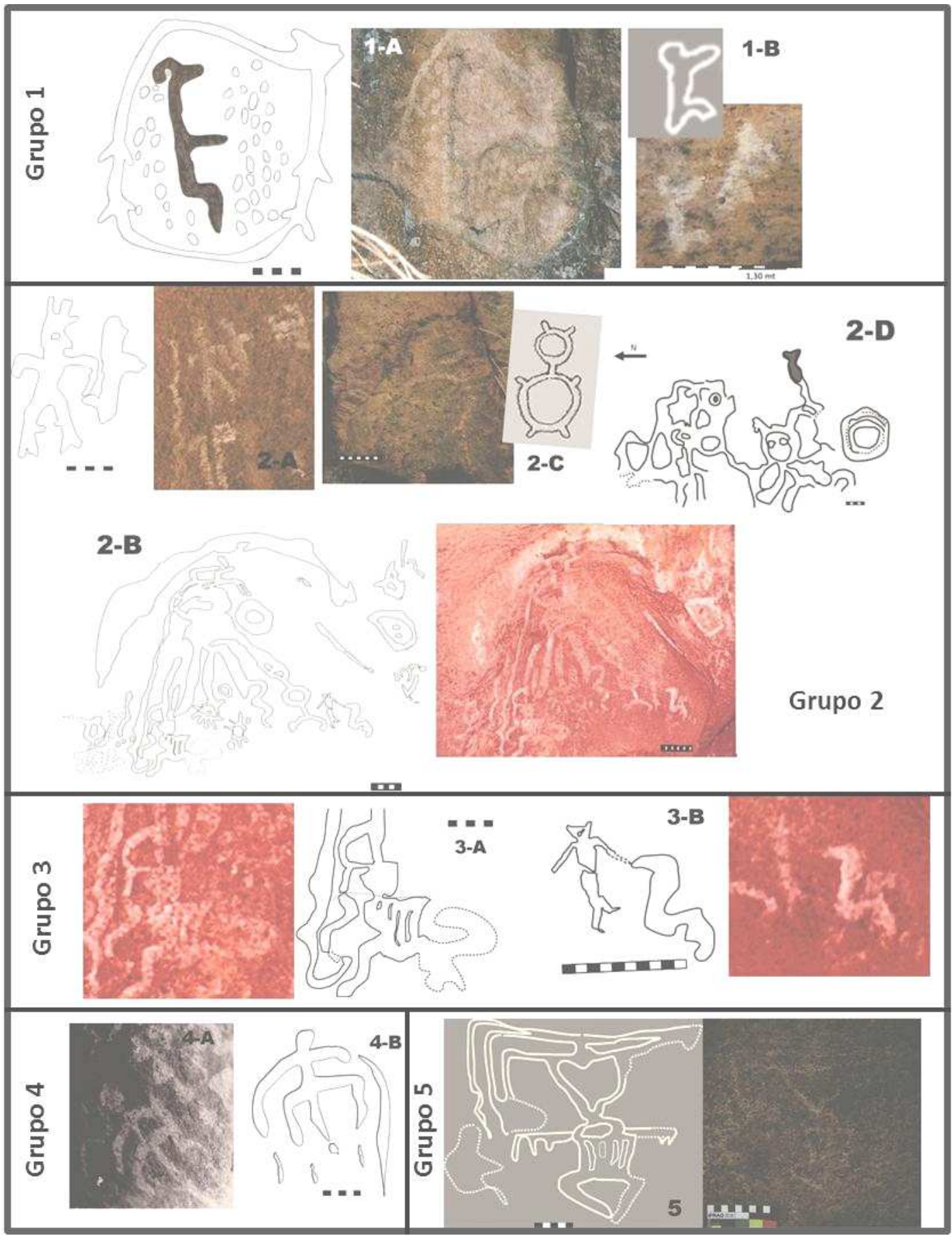

Figura 12. Grupos de motivos antropomorfos definidos para el área de estudio.

Grupo 1:A. UT I (LM), B. UT I (ADQ). Grupo 2: A. ADQ (UT I), B. LC (UT I), C. LM (UT I), D. LM (UT IIB). Grupo 3 A y B. LC (UT I). Grupo 4: A. LC (UT II), B.EQ (UT I). Grupo 5: LM (UT V). 
En el caso de LM, los antropomorfos grabados del grupo 2 y 4 comparten la misma orientación de panel hacia el norte y se ubican ambas a pocos centímetros del suelo en la entrada del valle, uno en la entrada oeste (UT V) y el otro al este (UT II). Se caracterizan por presentar tocados, como mencionan las relaciones españolas citadas por Pedersen (1959:54) "traen todos los mas en las tocas de las cabezas y tocados de lana hazen por galla muchas varilas largas de metal y al cavo dellas como cucharas" (Urquiza et al.2009).

\section{Consideraciones Finales}

Tanto los sitios septentrionales como los meridionales analizados, comparten una temática de motivos, siendo más intensa en ADQ y LM. En todos los sitios la técnica es pintado y sólo en LM se suma el grabado surco picado, siendo probablemente más tardíos que las pinturas (Urquiza et al. 2009).

Resulta llamativo el sitio ER ya que es donde se encuentra el único motivo pintado en rojo, predominando en los otros el color blanco. El sitio Las Mojarras presenta mayor variabilidad de técnicas de ejecución, con grabados (surco picado y surco picado profundo) y pintados en negro y blanco. En LM se registra una importante cantidad y variedad de motivos, siendo el único donde el arte es visible, ya que se localiza en paredones y bloques en la orilla de un arroyo junto a una senda actual, señalando tal vez una continuidad en el uso de los espacios para circular y transportar animales, lo que otorga al arte un carácter público, que podría relacionarse con el control de caminos, agua o bienes de circulación entre los distintos ambientes (Ibid). Así, se marca diferencia con los restantes sitios donde el arte se encuentra dentro de cuevas, tomando un carácter más privado "que tiene injerencia directa en el carácter restringido de la información transmitida y dirigida sólo hacia aquellos que ingresan, ocupan y construyen cotidianamente sus lugares..." (Recalde 2009: 50). En todos los sitios existe un fuerte vínculo entre las representaciones rupestres y los cursos de agua. El corredor de las Salinas desemboca en cercanías al valle de LM, donde el arte presenta mayor visibilidad y la representación de mayor envergadura. En el caso del motivo ubicado a gran altura, su tamaño, la técnica empleada, el contraste con el soporte y su tamaño, aseguró su visibilidad por personas que llegaban desde zonas desérticas como las salinas, sindicando tal vez su cercanía con agua y/o territorios de pastoreo de camélidos, ya sean viajeros del mismo grupo que el artista o que comparten los mismos códigos de identidad. Los sitios con representaciones poco visibles para viajeros o para aquellos que no conozcan su localización, significarían lugares especiales para un público interno y reducido, acaso destinados a evocar la memoria de un grupo o ser recurrido por cazadores y pastores. En estos casos el espectador se involucra con las representaciones en un vínculo más directo, logrando percibirlo de forma visual y táctil, transformándolo en un arte interactivo.

Hasta el momento continúa siendo notoria la subrepresentación de sitios con grabados en el área de estudio, con excepción del Cerro Veladero, donde ha sido descrito un solo grabado en surco no figurativo (Gardner 1931). Los grabados de Las Mojarras, únicos hasta el momento, se encuentran en rocas con patina natural fuerte donde el picado produce gran contraste. La pátina débil de los mismos, es parecida en todos los motivos, variando levemente los tonos en los surcos que registran líquenes. Nos permitimos especular entonces, en que los grabados se ejecutaron en un momento de ocupación o en diferentes muy próximos (Urquiza et al. 2009). En relación a las pinturas, como mencionamos, ER presenta motivos en rojo y blanco, análogamente a Máscaras y al área de Cerro Colorado. 
Berberián y Nielsen (1985) clasifican a los sitios con arte de Córdoba en dos grupos, incluimos en el segundo grupo a ER, en el primero a LM, y sumamos ADQ y EQ (en discrepancia con los autores) localizados en Suana.

Sobre los camélidos, todos se encuentran pintados en blanco y exhibiendo características propias del arte rupestre Formativo inicial y medio del Noroeste argentino (Aschero 1999,2000; Podestá 1988; Berenguer 1999). En ADQ un par de camélidos se encuentran de espaldas, uno invertido sobre el otro, y en LM sólo se encuentra el invertido, recordando a los de Cerro Veladero, Intihuasi y La Aguada (Figura 11). Los camélidos, ubicados en LM y ADQ, presentan cuatro patas y dos orejas como el Canon D definido por Recalde (2009:46) para el área oeste de Córdoba. No obstante, las semejanzas son más fuertes con Cerro Colorado, por lo que pensamos en un nuevo canon de camélidos.

Resulta llamativa la ausencia de aves, ya que sólo están presentes en las pinturas de LM y en paneles de La Aguada y del área de Cerro Colorado con los cuales presentan semejanzas (Cerro Colorado, Cerro del Sol, Cerro Veladero, Desmonte) (Figura 5). Las aves representadas en LM se asemejan a los motivos de la cerámica Sunchituyoj y Averías. También se observan semejanzas entre los motivos no figurativos pintados y los diseños de la cerámica Averías. Es probable que el arte rupestre de las Sierras Norte de Córdoba haya estado influenciado por las antiguas poblaciones del sur de la provincia de Santiago del Estero (González, 1998 y González y Pérez, 1972) basado esto en hallazgos de cerámica santiagueña en los sitios con representaciones rupestres, como es el caso de Suana. Por lo que debemos realizar comparaciones con los sitios la sierra de Guasayán, Quebrada de las Marcas, Casa del Tigre y Puerta Chiquita.

En general el arte no presenta superposiciones. En su mayoría las representaciones grabadas, y algunas pintadas, poseen una alta frecuencia de yuxtaposiciones (sensu Troncoso 2005), y en algunos casos las representaciones geométricas conforman figuras complejas "que impiden identificar claramente si nos encontramos ante un solo gran motivo o diferentes motivos pequeños unidos" (Troncoso op cit.). Los trazos verticales con círculos adosados y circunferencias cruzadas por un trazo (LM y ADQ: pintados y LM: grabados), guardan similitudes formales con los sitios del norte de Córdoba La Aguada, Máscaras, Copacabana, Cerro Puntudo y Cerro Colorado. En tanto que los trazos meandriformes se correlacionan estilísticamente con los sitios La Aguada, Cerro del Sol y Desmonte, y los circulares con La Aguada y Cerro Colorado. Para éste último, González (1998) infiere diferentes momentos, y si bien no menciona a las representaciones más antiguas, se continúan desde el inicio de la era cristiana hasta el siglo $\mathrm{V}$ con motivos de arco y flecha, seguidos por la presencia de alfarería chaco santiagueña hacia el siglo $\mathrm{X}$ y finalizando en el siglo XVI con motivos de conquistadores españoles en las pinturas rupestres. Por esto, los sitios de Suana podrían adscribirse entre los siglos V y $X$, de acuerdo a la cerámica recuperada y el motivo antropomorfo del grupo 2 .

Entre los grupos de antropomorfos planteados, se destaca el predominio de las pinturas por sobre los grabados. Las representaciones antropomorfas analizadas presentan semejanzas estilísticas con las pinturas de Cerro Puntudo para el área de estudio, y con los personajes del arte rupestre del sitio La Tunita (De La Fuente y Díaz Romero 1974, Nazar et al. 2010) y La Candelaria (Llamazares 1999) de la sierra de Ancasti y con algunas figuras de la cerámica estilo Aguada de los valles de Hualfín y Ambato (Prov. Catamarca) (González 1998, Gordillo 2009, Laguens 2006). Esta misma analogía se da con los grabados del cerro Las Marcas en el valle de Vinchina (Prov. La Rioja) (Callegari et al. 2009). 
Vignati (1939) asigna al sitio Máscaras una antigüedad anterior al siglo XVI, previo al contacto hispano-indígena, y por analogías en el arte, González (1980) lo vincula cronológicamente con La Aguada del sitio La Tunita, y Urquiza et al.(op. cit.) bajo el mismo criterio asigna este estilo a Las Mojarras. En este caso, también relacionamos a los antropomorfos del Grupo 2 (Figura 12), de El Quebrachal y Agua del Difunto Quinto, con los de La Tunita y La Candelaria (Catamarca), cerro Las Marcas (La Rioja) y Máscaras, Cerro Puntudo y Veladero (Córdoba). El resto de las representaciones de ADQ se asemejan a Máscaras. Los personajes antropomorfos de este grupo, muestran una distinción jerárquica y/o guerreros con armas, los que se presentan en el arte rupestre del NOA desde el Formativo Temprano (Korstanje y Aschero 1996). Los Grupos 4 y 5, asociados con motivos no figurativos, y realizados en bloques y aleros, es probable que correspondan a un momento temporal posterior, tal vez de contacto hispano indígena. El material recuperado en superficie es escaso, sin embargo, en LM se vincula a momentos agropastoriles, y en ADQ podría relacionarse con Sunchituyoj.

Si bien admitimos afinidades con el área sudeste de Catamarca, La Rioja y tal vez con el sur de Santiago del Estero, lo que adscribe tentativamente el arte rupestre de las Sierras Norte a una cronología relativa de entre fines del Formativo Tardío y el Período de Integración Regional, debemos realizar excavaciones sistemáticas con la finalidad de acercarnos a los modos de vida de los antiguos pobladores del norte de Córdoba, y demarcar un rango temporal más ajustado. Hasta contar con mayores asociaciones contextuales, inferimos para los sitios estudiados, en base a su ubicación geográfica y en las correlaciones estilísticas con otras áreas, que las sierras del Norte de Córdoba han sido puntos de flujo de bienes y de información visual entre los grupos humanos del SE de Catamarca, el este riojano y quizás del sur de Santiago del Estero. Estas personas probablemente recurrieron a los corredores naturales de las salinas en caravanas de llamas. Es sugerente y posible que el grupo estilístico afianzado en la representación de la figura humana, común de las Sierras Pampeanas, sea producto de éstas dinámicas sociales.

\section{Agradecimientos}

A Daniel Cosutta, María Celminia y Marcelo Castillo, así como a los Sres. Ferreyra y Valle. A Carlos Cónsole, Lincoln y Ariel Urquiza por sus invaluables aportes e interés. Nuestro especial agradecimiento para los evaluadores, quienes con sus valiosos comentarios mejoraron el manuscrito original.

\section{Notas}

1 Suana era un poblado de mineros dedicados a la explotación de granito para la confección de adoquines. Fue abandonado entre 1930 y 1940. El punzón de hueso y puntas líticas encontrados en sus inmediaciones, se encuentran en el Museo de Paleontología, Arqueología e Historia de la ciudad de Deán Funes (Prov. Córdoba).

\section{Bibliografía citada:}

Aschero, C. A.

1988. Pinturas rupestres, actividades y recursos naturales: un encuadre arqueológico.: Arqueología Contemporánea Argentina. Actualidad y perspectivas (ed. Por H. Yacobaccio) pp. 109-145. Ediciones Búsqueda, Buenos Aires.

1999. El Arte Rupestre del Desierto Puneño y el NOA. Arte Rupestre en los Andes de Capricornio (ed. Por J. Berenguer R. y F. Gallardo I.) pp. 97-135, Museo Chileno de Arte Precolombino y Banco de Santiago, Santiago de Chile. 
2000. Figuras Humanas, camélidos y espacios en la interacción circunpuneña. Arte en las Rocas. Arte rupestre, menhires y piedras de colores en la Argentina (ed. por M. Podestá y de Hoyos), pp.15-44. Sociedad Argentina de Antropología y Asociación Amigos del INAPL, Buenos Aires.

Aschero, C.A. y A.R. Martel.

2003-2005. El arte rupestre de Curuto-5.Antofagasta de la Sierra (Catamarca, Argentina). Cuadernos del INAPL 20: 47-72.

Berberián, E.E. y A.E. Nielsen.

1985. El Arte Rupestre de la Región serrana de la Provincia de Córdoba (Argentina). Manifestaciones Pictográficas. Comechingonia 3 (5): 15-30.

Berenguer, J.

1999. El evanescente lenguaje del arte rupestre en los Andes atacameños. En Arte rupestre en los Andes de Capricornio, J. Berenguer y F. Gallardo Eds., pp. 9-56. Museo Chileno de Arte Precolombino, Santiago.

Bonalumi, A.

1988. Características petrológicas y geoquímicas de los granitoides asociados a la mineralización de manganeso en el norte de la Provincia de Córdoba y sur de Santiago del Estero. $5^{\circ}$ Congreso Geológico Chileno, Actas 2: 47-61, Santiago de Chile.

Boman, E.

1908. Antiquités de la région andine de la République Argentine et du désert duAtacama. Imprimerie Nationale, París.

Cabrera, A.L.

1976. Regiones Fitogeográficas Argentinas. Enciclopedia Argentina de Agricultura y Jardinería, ACME, Buenos Aires.

Cocilovo, J., A. Marcelino.

1975. Dos nuevos grupos pictográficos de la provincia de Córdoba. Actas y Trabajos del Primer Congreso de Arqueología Argentina. Museo Histórico Provincial «Dr. Julio Marc». pp. 271-285. Buenos Aires

Codesio, M. y D. Bilenca

2004. Variación Estacional de un Ensamble de Aves en un Bosque Subtropical Semiárido del Chaco Argentino. Biotropica 36 (4): 544-554.

Callegari , A. L. Wisnieski, G,G. Spengler, G. Rodriguez y S. Aumont

2009. Nuevas manifestaciones del arte rupestre del oeste riojano. Su relación con el paisaje y con otras expresiones del Arte Aguada. Crónicas sobre la Piedra. Arte Rupestre de las Américas (ed. por M. Sepúlveda, L. Briones y J. Chacama), pp. 381-402. Arica, Chile.

De Aparicio, F.

1936. La antigua provincia de los comechingones. Historia de la Nación Argentina I: 381-428 (ed. Ricardo Levene) Editorial El Ateneo, Buenos Aires. 
De La Fuente, N.R y A.R. Díaz Romero

1974. Un conjunto de figuras antropomorfas del yacimiento "La Tunita”, Prov. de Catamarca. Revista del Instituto de Antropología (V): 35-57.

Elortegui Palacios, J., R.Lira, F. Poklepovic y M. J. Dorais.

2008. El granito calasuya: un intrusivo alcalifeldespático postcolisional en el batolito de Sierra Norte-Ambargasta, Córdoba. Revista de la Asociación Geológica Argentina 63 (3): 299-309.

Gardner, G.A.

1931. Rock paintings of North-West Córdoba. Oxford: at the Clarendon Press.UK

González, A.R.

1956-58. Reconocimiento arqueológico de la zona de Copacabana (Córdoba).

Separata de la Revista do Museo Paulista, Nova Serie. (X): 174-212.

1963. Las Pinturas Indígenas del Cerro Colorado. Revista Gacetika Nº 63.

1980. Arte Precolombino de la Argentina. Filmediciones Valero, $2^{\circ}$ Ed. Bs.As.

1998. Las pinturas indígenas de Cerro Colorado. Estudios N¹0. Centro de estudios avanzados de la Univ. Nac. Córdoba.

González, A.R. y Pérez Gollán, J.

1972. Historia Argentina. Argentina Indígena, víspera de la conquista. Editorial Paidos. Buenos Aires.

1998. Cultura de La Aguada. Arqueología y diseños. Arte precolombino. Filmediciones Valero, Buenos Aires.

Gordillo, I. 2009. Dominios y Recursos de la Imagen. Iconografía Cerámica del Valle de Ambato. Estudios Atacameños. Arqueología y Antropología Surandinas. N 37: 99-121. San Pedro de Atacama. Chile.

Korstanje, M.A. y C.A.Aschero.

1996. Arte Rupestre en los Valles El Bolsón y Las Cuevas (Catamarca, Argentina). Chungara 28 (1-2): 199-222.

Laguens, A. G.

2006. Continuidad y ruptura en procesos de diferenciación social en comunidades aldeanas del Valle de Ambato, Catamarca, Argentina. Chungara 38 (2): 211-222.

Llamazares, A.M.

1999. El arte rupestre de la cueva La Candelaria, provincia de Catamarca, Argentina. Publicaciones del CIFFYH (50): 1-26.

Llambías, E.J., Gregori, D., Basei.M., Varela, R. y C. Prozzi.

2003. Ignimbritas riolíticas neoproterozoicas en la Sierra Norte de Córdoba: ¿evidencia de un arco magmático temprano en el ciclo Pampeano?. Revista de la Asociación Geológica Argentina, 58 (4): 572-582.

Lugones, L.

1903. Las grutas pintadas del Cerro Colorado. 26 de marzo de 1903. Suplemento ilustrado, Diario La Nación. 
Morello, J. y S. Matteuci.

1999. Biodiversidad y fragmentación de los bosques en la Argentina. Biodiversidad y uso de la tierra: conceptos y ejemplos de Latinoamérica. (ed. por S. Mateucci, O. Solbrig, J. Morello y G. Halffter), pp. 463-498. Editorial Universitaria de Buenos Aires, Buenos Aires.

Nazar, D.C., L. Gheco y C. Barot.

2010. El arte rupestre de La Tunita y La Toma, cuenca media e inferior de los ríos Chico y Los Molinos, provincia de Catamarca, Argentina. Resúmenes del VIII SIAR.pp131-135. San Miguel de Tucumán.

Ochoa, G.S.

2008. Análisis e interpretaciones de las representaciones rupestres de Córdoba en publicaciones de fines del S.XIX hasta los 80' del S. XX. Revista del Museo de Antropología 1(1) 41-50.

Pedersen, A.

1953-1954. El Infrarrojo y su aplicación en la investigación de pinturas rupestres. Runa VI (1-2): 216-219. Archivo para las Ciencias del Hombre. Facultad de Filosofía y Letras, Universidad de Buenos Aires.

1959. Las Pinturas Rupestres de las Sierras de Córdoba (República Argentina) y sus Normas Convencionales de Representación. De los Anales de Parques Nacionales. (VII): 51-59.

Pérez Gollán, J.

1968. Arte Rupestre de Cerro Colorado. Filmediciones Valero, Bs. As.

Podestá, M.M.

1986-87. Arte Rupestre en Asentamientos cazadores Recolectores y agroalfareros en la Puna Sur Argentina: Antofagasta de la Sierra, Catamarca. Relaciones de la Sociedad Argentina de Antropología XVII (1):241-263. Buenos Aires.

Recalde, A.

2009. Diferentes entre Iguales: El Papel del Arte Rupestre en la Reafirmación de Identidades en el Sur del Valle de Guasapampa (Córdoba, Argentina) Boletín del Museo Chileno de Arte Precolombino 14 (2): 39-56.

Recalde, A y E. Berberían.

2005. El Arte Rupestre de Argentina Indígena. Centro. Union Acadeique Intrenationale-Academia Nacional de la Historia.GAC. Buenos Aires.

Scattolin, M.C.

2006. Categoremas indígenas y designaciones arqueológicas en el noroeste argentino prehispánico. Chungará 38 (2): 185- 196.

Serrano, A.

1945. Los Comenchingones. Serie aborígenes argentinos VI. Instituto de Arqueología, Lingüística y Folclore, Córdoba. 
Troncoso, A.

2003. Proposición de Estilos para el Arte Rupestre del Valle de Putaendo, Curso Superior del Río Aconcagua. Chungara 35 (2):209-231.

2005. Hacia una semiótica del arte rupestre de la cuenca superior del río Aconcagua, Chile Central. Chungara 37 (1): 21-35.

Urquiza, S. V.

2006. Revisiones arqueológicas del norte de Córdoba. Noticias Históricas del Norte Cordobés. Ediciones La Posta, pp. 167-171. Deán Funes, Córdoba.

Urquiza, S.V.; C.A. Aschero y L. R. Urquiza.

2009. Arte Rupestre en las Sierras Pampeanas: Sitio Las Mojarras. Crónicas sobre la Piedra. Arte Rupestre de las Américas (ed. por M. Sepúlveda Retama, L. Briones Morales, J. Chacama Rodríguez), pp. 403-412. Arica, Chile.

Vignati, M.A.

1939. El Arte Parietal Indígena en Máscaras. Al Norte de la Provincia de Córdoba. Notas del Museo de La Plata. Tomo IV. Antropología 14: 264-284. 